\title{
Optimal and continuous anaemia control in a cohort of dialysis patients in Switzerland
}

\author{
Claudine M Mathieu ${ }^{\dagger 1}$, Daniel Teta ${ }^{\dagger 1}$, Nathalie Lötscher ${ }^{2}$, Dela Golshayan ${ }^{1}$, \\ Luca Gabutti ${ }^{3}$, Denes Kiss ${ }^{4}$, Pierre-Yves Martin ${ }^{5}$ and Michel Burnier*1
}

\begin{abstract}
Address: ${ }^{1}$ University Hospital CHUV, Department of Nephrology, Lausanne, Switzerland, ${ }^{2}$ Roche (Pharma) Switzerland Ltd, Reinach, Switzerland, ${ }^{3}$ Ospedale Regionale, Department of Nephrology, Locarno, Switzerland, ${ }^{4}$ Kantonsspital, Department of Nephrology, Liestal, Switzerland and ${ }^{5}$ University Hospital HCUG, Department of Nephrology, Geneva, Switzerland

Email: Claudine M Mathieu - clm.mathieu@wanadoo.fr; Daniel Teta - Daniel.Teta@chuv.ch; Nathalie Lötscher - Nathalie.Loetscher@ubs.com; Dela Golshayan - Dela.Golshayan@chuv.ch; Luca Gabutti - luca.gabutti@eoc.ch; Denes Kiss - denes.kiss@ksli.ch; Pierre-Yves Martin - pierreyves.martin@hcuge.ch; Michel Burnier* - Michel.Burnier@chuv.ch

* Corresponding author †Equal contributors
\end{abstract}

Published: II December 2008

BMC Nephrology 2008, 9:16 doi:10.1/86/147|-2369-9-16

This article is available from: http://www.biomedcentral.com/I47/-2369/9/16

(C) 2008 Mathieu et al; licensee BioMed Central Ltd.

This is an Open Access article distributed under the terms of the Creative Commons Attribution License (http://creativecommons.org/licenses/by/2.0), which permits unrestricted use, distribution, and reproduction in any medium, provided the original work is properly cited.
Received: 2 January 2008

Accepted: II December 2008

\begin{abstract}
Background: Guidelines for the management of anaemia in patients with chronic kidney disease (CKD) recommend a minimal haemoglobin $(\mathrm{Hb})$ target of $\mathrm{II} \mathrm{g} / \mathrm{dL}$. Recent surveys indicate that this requirement is not met in many patients in Europe. In most studies, $\mathrm{Hb}$ is only assessed over a short-term period. The aim of this study was to examine the control of anaemia over a continuous long-term period in Switzerland.
\end{abstract}

Methods: A prospective multi-centre observational study was conducted in dialysed patients treated with recombinant human epoetin (EPO) beta, over a one-year follow-up period, with monthly assessments of anaemia parameters.

Results: Three hundred and fifty patients from 27 centres, representing $14 \%$ of the dialysis population in Switzerland, were included. Mean $\mathrm{Hb}$ was $11.9 \pm 1.0 \mathrm{~g} / \mathrm{dL}$, and remained stable over time. Eighty-five \% of the patients achieved mean $\mathrm{Hb} \geq 1 \mathrm{I} \mathrm{g} / \mathrm{dL}$. Mean EPO dose was $155 \pm 1 / 8 \mathrm{IU} /$ $\mathrm{kg} /$ week, being delivered mostly by subcutaneous route (64-7/\%). Mean serum ferritin and transferrin saturation were $435 \pm 253 \mu \mathrm{g} / \mathrm{L}$ and $30 \pm 11 \%$, respectively. At month I2, adequate iron stores were found in $72.5 \%$ of patients, whereas absolute and functional iron deficiencies were observed in only $5.1 \%$ and $17.8 \%$, respectively. Multivariate analysis showed that diabetes unexpectedly influenced $\mathrm{Hb}$ towards higher levels $(I 2 . \mathrm{I} \pm 0.9 \mathrm{~g} / \mathrm{dL} ; \mathrm{p}=0.02)$. One year survival was significantly higher in patients with $\mathrm{Hb} \geq 1 \mathrm{I} g / \mathrm{dL}$ than in those with $\mathrm{Hb}<1 \mathrm{I} / \mathrm{dL}(19.7 \% \mathrm{vs} 7.3 \%, \mathrm{P}$ $=0.006$ ).

Conclusion: In comparison to European studies of reference, this survey shows a remarkable and continuous control of anaemia in Swiss dialysis centres. These results were reached through moderately high EPO doses, mostly given subcutaneously, and careful iron therapy management. 


\section{Background}

Effective anaemia control in dialysis patients is associated with many benefits, including lower mortality, morbidity and better quality of life [1-6]. Despite significant improvement in the last few years, recent surveys, such as the European Survey in Anaemia Management (ESAM) 2003 [7] and the Dialysis Outcomes and Practice Pattern Study II (DOPPS II) [8], show that the minimal haemoglobin (Hb) target of $11 \mathrm{~g} / \mathrm{dL}$, proposed by the European Best Practice Guidelines (EBPG) [9] and the Kidney Disease Outcomes Quality Initiative (K/DOQI) [10], was not achieved in many patients. In Switzerland, only few data on the control of anaemia in dialysed patients is available. In ESAM 1998 [11], Switzerland achieved mean $\mathrm{Hb}$ of $11.7 \mathrm{~g} / \mathrm{dL}$ (mean Hb of all countries was $11.4 \mathrm{~g} / \mathrm{dL}$ ). In ESAM 1998 and 2003, the proportion of patients above the minimal target of $\mathrm{Hb}>11 \mathrm{~g} / \mathrm{dL}$ in this country were 65.1 and $78.9 \%$, respectively, leaving many patients under the target. It is noteworthy that ESAM 2003 was based on a 1 day assessment, whereas data from ESAM 1998 has been collected during a six-months follow-up period. It is known that $\mathrm{Hb}$ is fluctuating during long term observations in dialysed patients [12-14]. Thus, we feel it would be meaningful to study: A) the quality of anaemia control in dialysed patients in Switzerland; B) if the control of anaemia and its treatment parameters could be maintained over a long period of time, C) if co-morbidities may modulate Hb level and EPO dose, and D) if anaemia management has improved when compared with earlier assessments.

\section{Methods \\ Study design and data collection}

This study was designed as a prospective, non-randomized, observational survey. Patients were recruited from November 2002 to March 2004. For each patient, the observation period lasted 12 months. A concise, fourpages report form was used for collecting baseline demographic data, clinical and laboratory parameters, as well as anaemia treatment modalities at study entry, and then monthly. The follow-up was only interrupted in the event of a death, a renal transplantation, or if the patient was lost to follow-up. Details of the study design and data collection are summarized in figure 1. The recruitment was performed in 27 dialysis centres, on a voluntary basis. There were 3 university-based centres, 17 regional-based and 7 private dialysis centres. According to Swiss law, an informed consent is not needed for this type of survey. No change in therapeutic strategy was requested during the observational period. Additionally, a questionnaire was sent to the participating centres, asking for centre-specific targets for anaemia treatment such as $\mathrm{Hb}$, serum ferritin and transferrin saturation (TSAT).
Three categories of iron status were defined: 1) absolute iron deficiency (ferritin $<100 \mu \mathrm{g} / \mathrm{L}$ ); 2) functional iron deficiency (ferritin $\geq 100 \mu \mathrm{g} / \mathrm{L}$ and TSAT $<20 \%$ ); and 3) adequate iron status (ferritin $\geq 100<800 \mu \mathrm{g} / \mathrm{L}$ and TSAT $\geq 20 \%$ ).

\section{Selection of patients}

The study population were adult patients undergoing maintenance renal replacement therapy, by either haemodialysis, haemodiafiltration or peritoneal dialysis. No minimal time on dialysis was requested. Adequate iron status (ferritin $\geq 200 \mu \mathrm{g} / \mathrm{l}$ and TSAT $\geq 20 \%$ ) was recommended but not mandatory to be enrolled for the study. Inclusion criteria were: i) age of $\geq 18$ years; ii) either epoetin (EPO) pre-treated (any type of EPO) or EPO-naive patients with newly diagnosed renal anaemia; iii) patients had to be exclusively on EPO beta during the course of the study. Exclusion criteria were the following: unstable angina pectoris, untreated uncontrolled hypertension, haemoglobinopathy, haemolysis, gastrointestinal bleeding, acute infection or unstable systemic inflammatory disease, epilepsy, pregnancy, lactation, deficiency of vitamin B12 (<200 ng/L), deficiency of acid folic $(<2 \mu \mathrm{g} / \mathrm{L})$, planned surgery during the survey period (except fistula surgery), known hypersensitivity to EPO beta.

Participating centres were asked to include as many patients as possible, on a voluntary basis, meeting the inclusion/exclusion criteria. Ten dialysis centres included more than $80 \%$ of all their patients treated with epoetin beta, and 15 centres in total included more than $60 \%$ of their patients receiving epoetin beta, contributing to $71 \%$ of the patients included in this survey.

\section{Data analysis}

Simple statistical analyses were performed in Excel 2002 and for more complex statistics the SAS statistical program version 8.2 (SAS, Institute, Cary NC, USA) was used. Standard descriptive statistics (mean, standard deviation, confidence interval) were calculated for all variables including $\mathrm{Hb}$, EPO dose, serum ferritin and TSAT. Means were calculated on an individual basis (per patient) for each month and thereafter and thereafter the means of the monthly data were used to calculate the one year average mean value for example for hemoglobin. Categorical variables were presented in absolute number and percentage and were compared with the $\mathrm{X}^{2}$-test whereas continuous variables with the Student's t-test or Wilcoxon two-sample test, where appropriate. The ANOVA model was used for the efficacy comparison of the different routes of administration. The Kaplan Meier analysis was taken to calculate survival probabilities. In the patients whose follow-up was interrupted, the data were collected and analysed 
Survey start December 2003 1
Survey end December 2004

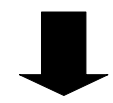

Visits

Baseline

6 months

12 months

Baseline
Medical history,
Epoetin beta dose,
frequency, route of
administration,
Laboratory data $(\mathrm{Hb}$,
Ferritin, transferrin
saturation (TSAT)

Baseline

Medical history, Epoetin beta dose, frequency, route of administration, Laboratory data $(\mathrm{Hb}$ saturation (TSAT)

\author{
Monthly reports (M1- \\ M12) \\ Weight \\ EPO dose, frequency, \\ route of administration \\ Laboratory data $(\mathrm{Hb}$, \\ ferritin, TSAT), \\ Concomitant anaemia \\ therapy
}

Final report

Questionnaire assessing targets in the treatment of renal anemia

\section{Figure I}

Study design. This was a prospective, observational survey in selected patients lasting from December 2003 (for the first patients included) to March 2005 (for the last patients included). Each single patient was observed during 12 months. Demographic and medical parameters, as specified in the figure, were collected at baseline, and then on a monthly basis.

until the last observation. The reasons for the interruption of follow-up were: death (33), transplantation [7], unknown reason [1]. Rare intermediate missing values of patients ( $\mathrm{Hb}$, body weight, EPO dose, administration frequency, route of administration), who received at least one survey medication, were replaced by using the last observation carried forward method (LOCF).

Univariate analysis was performed for $\mathrm{Hb}$ and EPO dose regarding concomitant diseases, diagnosis, age and gender. A multivariate analysis was performed which included the covariates with $\mathrm{p}<0.05$ in the univariate analysis. All statistical tests were two-sided and the significance was proofed on a 0.05 p-level.

\section{Results}

Demographics and baseline characteristics

Three hundred and seventy patients from 27 dialysis centres were initially recruited. Twenty patients were excluded, because of major surgery $(n=4)$, bleeding $(n=$ $2)$, and missing data $(n=14)$. Three hundred and fifty patients were finally analysed, representing 14\% of the total dialysis population of Switzerland. Patients characteristics are shown in table 1 . Causes of end stage renal disease (ESRD) and co-morbidities are described in table 2 and 3, respectively. Hypertension, diabetes and ischaemic heart disease were the most common concomitant pathologies; these findings are comparable to ESAM 2003, though in the latter, $20.2 \%$ of the patients suffered of peripheral vascular disease, compared to only $4.6 \%$ in our survey.

\section{Longitudinal assessment of $\mathrm{Hb}$, iron status and EPO dose} Month to month assessments of $\mathrm{Hb}$, EPO dose and iron status, over the one-year observation period, are summarized graphically in figure 2 . The overall mean Hb concentration based on the means of per patient values was 11.9 $\pm 1.0 \mathrm{~g} / \mathrm{dL}$, with a slight trend to increase over time, although not significantly. Mean weekly EPO dose was $155 \pm 118 \mathrm{IU} / \mathrm{kg} /$ week, with a greater trend to increase from baseline to month 12 (but not significant). Mean 
Table I: Patients characteristics at baseline

\begin{tabular}{lc}
\hline $\mathbf{( n}=\mathbf{3 5 0}$ patients) & Mean $\mathbf{\text { SD }}$ \\
\hline Age (years) & $63.9 \pm 14.5$ \\
Range & $|8-9|$ \\
Female (\%) & $\mid 45(41.4)$ \\
Male (\%) & $205(58.5)$ \\
Haemodialysis/Haemodiafiltration (\%) & $332(94.9)$ \\
Peritoneal dialysis (\%) & $18(5.1)$ \\
EPO pre-treated $(\%)$ & $330(94.3)$ \\
EPO naive $(\%)$ & $20(5.7)$ \\
Body weight $(\mathrm{kg})$ & $69.9 \pm 15.3$ \\
Range & $40-129$ \\
Haemoglobin $(\mathrm{g} / \mathrm{dL})$ & $11.7 \pm 1.4$ \\
Range & $6.8-15.5$ \\
Serum ferritin $(\mu \mathrm{g} / \mathrm{L})$ & $404 \pm 293$ \\
& \\
TSAT $(\%)$ & $31 \pm 15$ \\
\hline
\end{tabular}

serum ferritin and TSAT were $435 \pm 253 \mu \mathrm{g} / \mathrm{L}$ and $30 \pm$ $11 \%$, respectively, with no significant variations.

The overall distribution of mean $\mathrm{Hb}$ is shown in figure 3 . Eighty five $\%$ of the patients achieved mean $\mathrm{Hb} \geq 11 \mathrm{~g} / \mathrm{dL}$ and $44 \%$ had mean $\mathrm{Hb} \geq 12 \mathrm{~g} / \mathrm{dL}$. The relationship between $\mathrm{Hb}$ and EPO dose was examined. The requirement of EPO for each section of mean Hb level is shown in the figure. Mean weekly EPO dose was significantly lower $(\mathrm{p}<0.0001)$ in patients with mean $\mathrm{Hb} \geq 11 \mathrm{~g} / \mathrm{dL}$ (137 $\pm 86 \mathrm{IU} / \mathrm{kg} /$ week; 95\% CI: $127-146 \mathrm{IU} / \mathrm{kg} /$ week) as compared to patients with mean $\mathrm{Hb}<11 \mathrm{~g} / \mathrm{dL}(255 \pm 194$ IU/kg/week; 95\% CI: 203-307 IU/kg/week). A significant negative correlation was found between overall mean EPO dose and mean Hb level $(\mathrm{r}=-0.21 ; \mathrm{p}<0.0001)$.

\section{Effect of gender, age and co-morbidities}

Mean $\mathrm{Hb}$ (calculated as described above in figure 3 ) in males was significantly higher than in females $(12.0 \pm 0.1$ versus $11.7 \pm 1.0 \mathrm{~g} / \mathrm{dL}, \mathrm{p}=0.01)$. Mean $\mathrm{EPO}$ dose was lower in men $(146 \pm 112 \mathrm{IU} / \mathrm{kg} /$ week $)$ than in women $(167 \pm 124 \mathrm{IU} / \mathrm{kg} /$ week $)$, but this difference was not significant $(\mathrm{p}=0.11)$.

Table 2: Causes of end-stage renal disease

\begin{tabular}{ll}
\hline Primary Renal Diagnosis & n (\%) \\
\hline Glomerulonephritis & $78(22.3)$ \\
Diabetic nephropathy & $75(21.3)$ \\
Hypertension/vascular nephropathy & $74(21.1)$ \\
Pyelonephritis/interstitial nephritis & $61(17.4)$ \\
Polycystic kidney disease & $27(7.7)$ \\
Unclear/Multifactorial & $13(3.7)$ \\
Miscellaneous causes & $11(3.1)$ \\
Malignancies & $9(2.6)$ \\
Missing & $12(3.4)$ \\
\hline
\end{tabular}

Patients could be recorded with more than one primary diagnosis.
Table 3: Co-morbidities

\begin{tabular}{|c|c|c|}
\hline & $\mathbf{n}$ & $\%$ \\
\hline Hypertension & 213 & 60.9 \\
\hline Diabetes ${ }^{\prime}$ & 96 & 27.4 \\
\hline Coronary artery disease & 88 & 25.1 \\
\hline Congestive heart failure & 55 & 15.7 \\
\hline Other cardiac diseases ${ }^{2}$ & 17 & 4.9 \\
\hline Vascular diseases ${ }^{3}$ & 16 & 4.6 \\
\hline Cancer $(\mathrm{ca})^{4}$ & 14 & 4.0 \\
\hline Metabolic disorders ${ }^{5}$ & 7 & 2.0 \\
\hline Hepatological disorders ${ }^{6}$ & 7 & 2.0 \\
\hline Chronic obstructive pulmonary disease (COPD) & 5 & 1.4 \\
\hline Hyperparathyroidism & 4 & I.I \\
\hline Others (nephrectomy/ciclosporine nephropathy) & 3 & 0.9 \\
\hline Amyloidosis & I & 0.2 \\
\hline \multicolumn{3}{|c|}{$\begin{array}{l}\text { I Diabetes (overall): including reported as primary diagnosis ( } \mathrm{n}=75 \\
\text { patients) } \\
{ }^{2} \text { Aneurysms (2); Mitral insufficiency (3); Paroxysmal tachycardia (I); } \\
\text { Pericarditis (I); Valvulopathy (I); Replacement of aortic valve (I) } \\
\text { Ischemic cardiopathy (8) } \\
{ }^{3} \text { Arteriosclerosis, arteriopathy, polyarteriovascular disease (I2); } \\
\text { Cerebrovascular disorder (3); bleeding(I); } \\
{ }^{4} \text { Cancer: reported as concomitant diseases: prostate ca (2); ear-nose- } \\
\text { throat ca (I); stomach ca (I); others and unknown (I0) } \\
\text { 5Obesity(3); Hypercholesterolaemia (I); Thyroiditis (I); Gout (2) } \\
6 \text { Liver transplantation (I); Liver cirrhosis (4); Pancreatitis (2) } \\
\text { Patients could be recorded under more than one co-morbidity. }\end{array}$} \\
\hline
\end{tabular}

The influence of age was not significant. However, mean EPO dose tended to be higher in women younger than 50 years compared to women older than $50(199 \pm 153$ versus $159 \pm 116 \mathrm{IU} / \mathrm{kg} /$ week; $\mathrm{p}=0.21$ ).

The influence of co-morbidities and primary renal diagnosis on mean $\mathrm{Hb}$ and EPO dose is shown in figure 4 . Mean $\mathrm{Hb}$ was $\geq 11 \mathrm{~g} / \mathrm{dL}$ in all subgroups, but varied according to co-morbidities and specific renal diagnosis. In multivariate analysis, diabetes was found to influence $\mathrm{Hb}$ towards a higher level $(\mathrm{p}=0.004)$ and EPO requirements towards lower doses $(\mathrm{p}=0.0004)$. Glomerulonephritis as a primary renal diagnosis influenced EPO towards a higher dose $(\mathrm{p}=0.008)$, but not $\mathrm{Hb}$.

\section{EPO administration and dose}

At baseline, $71.1 \%$ of the patients received EPO beta subcutaneously. The proportion of intravenous administration tended to increase from 29 to $36 \%$ over time. A stable proportion of 68 to $70 \%$ of patients were treated with a once weekly regimen. Mean $\mathrm{Hb}$ was identical in the patients treated by intravenous or subcutaneous route. However, EPO dose was significantly lower in favour of the subcutaneous administration $(114 \pm 14$ versus $187 \pm$ $25 \mathrm{IU} / \mathrm{kg} /$ week, $\mathrm{p}=0.035$ ). For an identical mean $\mathrm{Hb}$ of $11.9 \mathrm{~g} / \mathrm{dL}$, patients treated once a week required a significantly lower EPO dose compared to patients treated 2 or 3 times per week $(129 \pm 103$ versus $229 \pm 105 \mathrm{IU} / \mathrm{kg} /$ week, $\mathrm{p}<0.0001$ ). This result is not surprising and only reflects 

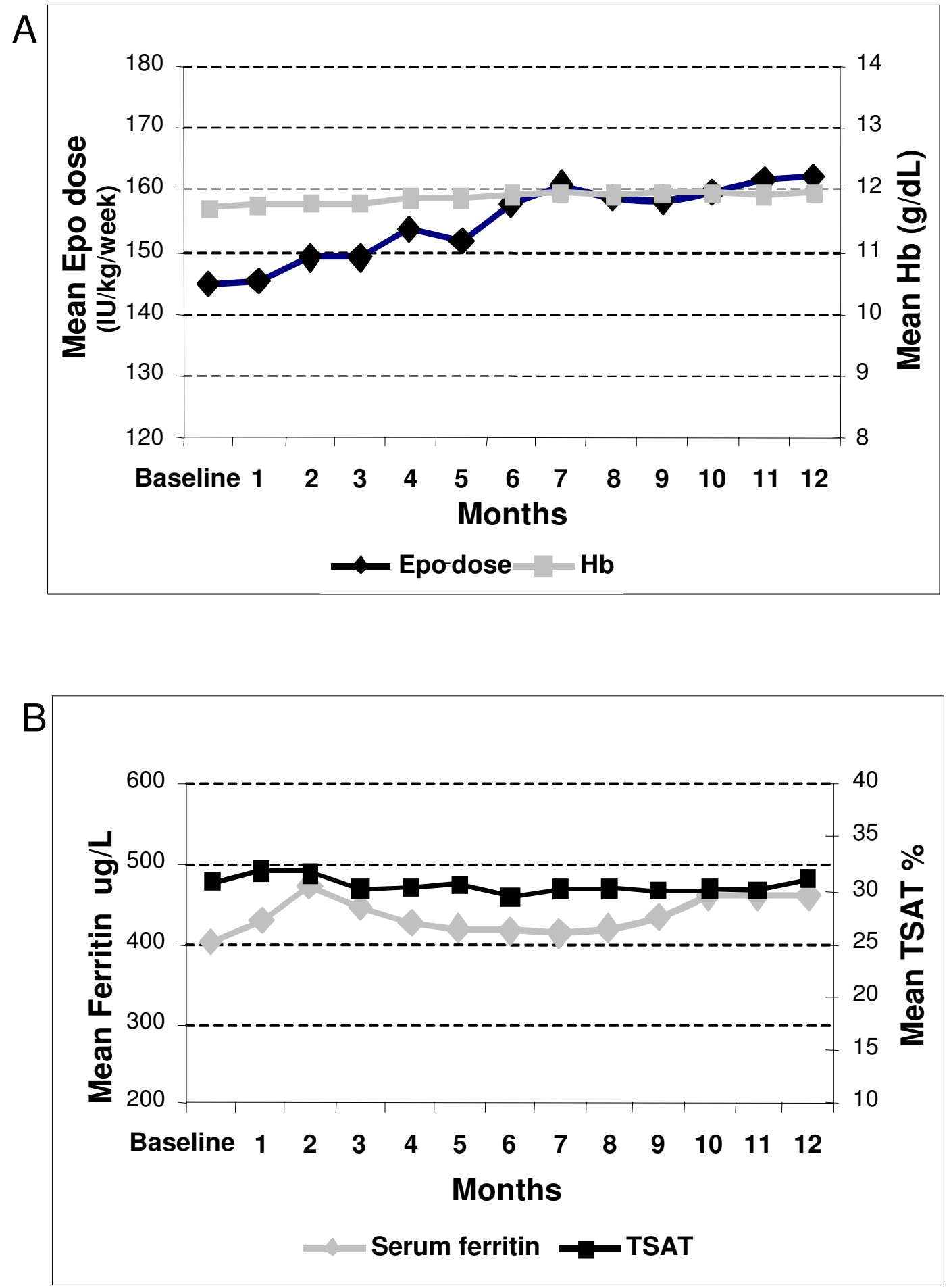

Figure 2

Monthly variations: month to month variations of mean $\mathrm{Hb}$ and EPO dose (upper panel $\mathrm{A}$ ) and iron status (ferritin and transferrin saturation, TSAT, lower panel B) over the one-year observation period. 


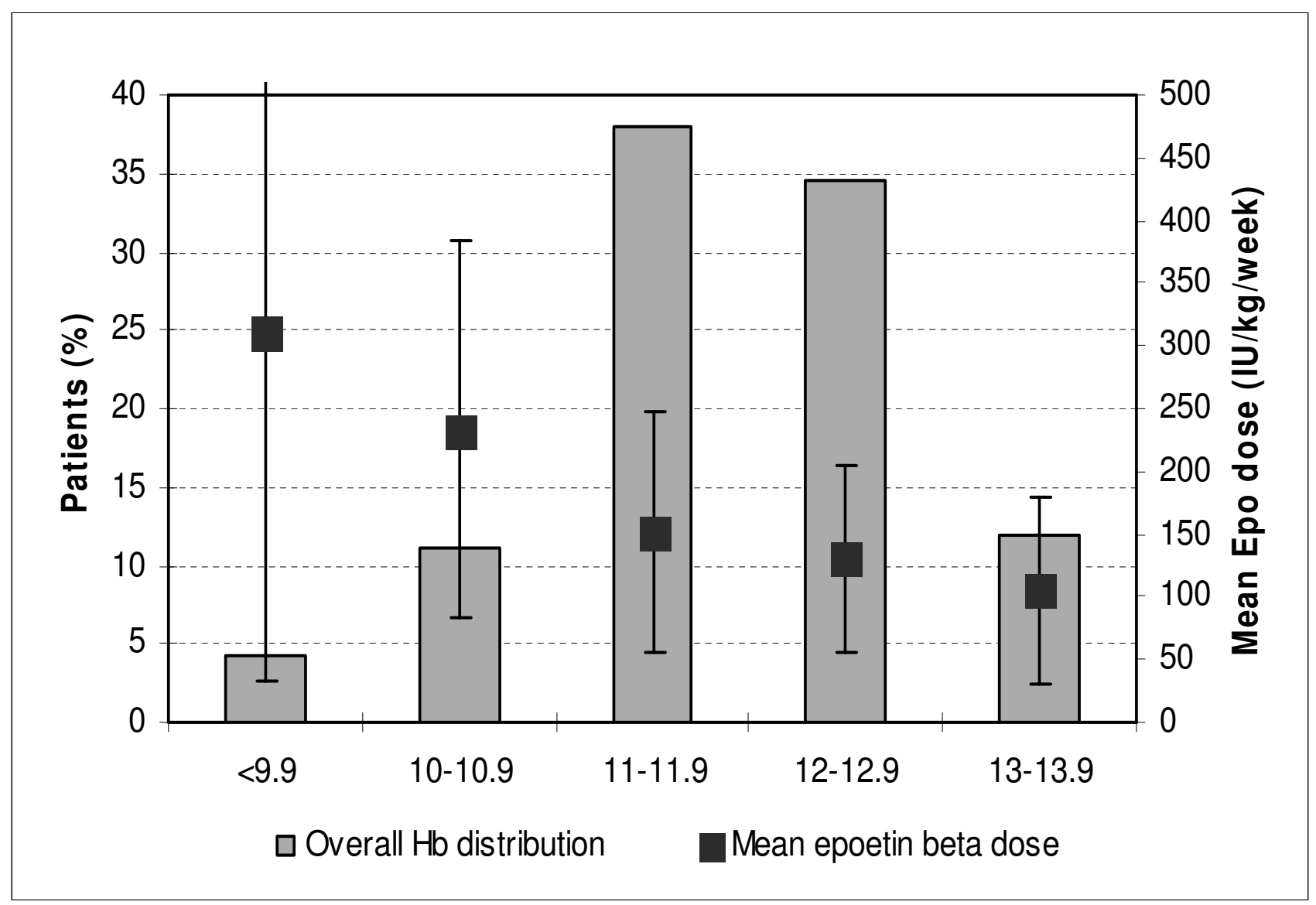

Figure 3

Mean $\mathrm{Hb}$ distribution over the follow-up period. Mean hemoglobin and EPO doses were first calculated on a per patient basis monthly and then over one year. Finally, the mean was calculated for the entire population with one mean per patient. The same was done for the EPO doses. Then, $5 \mathrm{Hb}$ subgroups have been defined, according to sections of I g/dL.

the way epoetin beta is prescribed by Swiss nephrologists: low doses are generally given once a week, whereas higher doses (>10'000 IU/week) are divided into 2 or 3 injections.

Fifteen patients $(4.3 \%)$ were found to be resistant to epoetin beta, defined by EPO doses higher than $300 \mathrm{IU} / \mathrm{kg} /$ week and $\mathrm{Hb}<11 \mathrm{~g} / \mathrm{dL}$. The co-morbidities of these patients were the following: coronary artery disease [4], heart failure [3], other cardiac diseases [1], diabetes[2], cancer [2], hypertension [4], liver disorder [1], chronic inflammation [1].

\section{Iron administration, iron status and adjuvant treatment of anaemia}

In addition to EPO therapy, 97\% of the patients received at baseline anti-anaemia adjuvant medication. Two hundred and thirty-two (68\%) patients received iron substitution, intravenously $(\mathrm{n}=187)$, orally $(\mathrm{n}=21)$ or not specified $(\mathrm{n}=24)$. About $13 \%$ of the patients received vitamins (including vitamin B12, vitamin $\mathrm{C}$ and folic acid). Transfusions were required in $8(2.2 \%)$ patients.

Ninety-two, 91 and $92 \%$ of the patients had serum ferritin of $\geq 100 \mu \mathrm{g} / \mathrm{L}$ at baseline, month 6 and month 12 , respectively. The percentage of patients with absolute iron deficiency ranged from 5.1 to $9.7 \%$ at any time during the observation period. At month 12, adequate iron status was found in $72.5 \%$ and functional iron deficiency in $17.8 \%$ of patients. The upper recommended limit of 800 $\mu \mathrm{g} / \mathrm{L}$ was exceeded in $7.1 \%$ of the patients in this survey, ranging from 5.7 to $11.1 \%$ over the 12 -months observation period. Sixty \% of our patients were within the optimal ferritin target $(200-500 \mu \mathrm{g} / \mathrm{L})$ recommended by the EBPG.

Mean EPO dose and mean Hb level with respect to iron status are shown in figure 5. Overall, patients with "ade- 


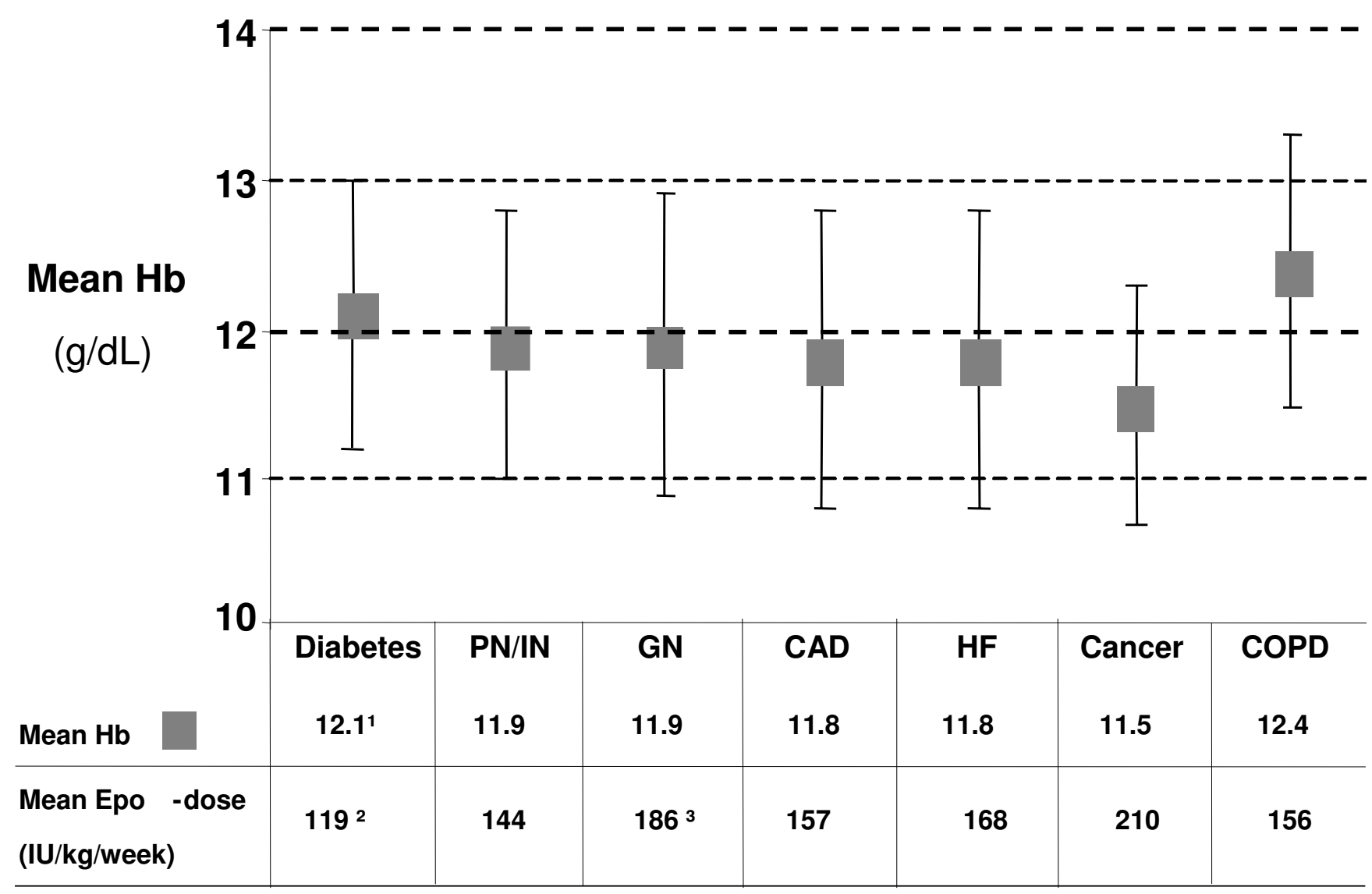

\section{Figure 4}

$\mathrm{Hb}$ and EPO dose, according to co-morbidities and/or primary renal diagnosis. The mean $\pm \mathrm{SD}$ of $\mathrm{Hb}$ and $\mathrm{EPO}$ doses as calculated in figure 3 are shown according to comorbidities or the primary renal diagnosis. Diabetes: $n=96$; pyelonephritis/interstitial nephritis (PN/IN): $n=6 I$; glomerulonephritis $(G N): n=78$; coronary artery disease $(C A D)$ : $n=88$; congestive heart failure $(\mathrm{HF}): \mathrm{n}=55$; cancer $(\mathrm{ca}): \mathrm{n}=\mathrm{I} 4$ (prostate ca $(\mathrm{n}=2)$, ear-nose-throat ca $(\mathrm{n}=\mathrm{I})$, stomach ca $(\mathrm{n}=\mathrm{I})$, others ca non specified $(n=10)$; chronic obstructive pulmonary disease $(C O P D): n=5 .{ }^{1} p=0.004 ;{ }^{2} p=0.003 ;{ }^{3} p=0.008$.

quate iron status" had the highest $\mathrm{Hb}$ with the lowest EPO dose. At month 6 and 12, patients with "absolute iron deficiency" increased their $\mathrm{Hb}(\mathrm{p}=0.0004$ at month 6 , and 0.03 at month 12) compared to baseline values. These patients also needed less EPO $(\mathrm{p}=0.008$ at month 6 and $\mathrm{p}=\mathrm{ns}$ at month 12, vs at baseline). The group "functional iron deficiency" had the lowest Hb level at month 6 and 12, despite the use of the highest EPO dose $(>200$ $\mathrm{IU} / \mathrm{kg} /$ week).

\section{Analysis of mortality: effect of $\mathrm{Hb}$ and EPO dose}

Thirty-three patients (9.4\%) died during the follow-up. Patients with mean $\mathrm{Hb} \geq 11 \mathrm{~g} / \mathrm{dL}$ at baseline had a significantly better survival compared to patients with mean $\mathrm{Hb}$ $<11 \mathrm{~g} / \mathrm{dL}$ (mortality rate: $7.3 \%$ vs $19.7 \%$, respectively; $\mathrm{p}=$ $0.006)$. Patients with mean $\mathrm{Hb} \geq 12 \mathrm{~g} / \mathrm{dL}$ at baseline showed a mortality rate of $7 \%$ at one year, whereas those with mean $\mathrm{Hb}<12 \mathrm{~g} / \mathrm{dL}$ had a mortality rate of $11.5 \%$, but this difference did not reach statistical significance.

As seen in figure $4, \mathrm{Hb}$ was partially determined by comorbidities, which represents a non modifiable factor for physicians. As Hb level was associated with mortality, we questioned whether EPO dose, a physician-dependent component of anaemia control, was associated with mortality, regardless of $\mathrm{Hb}$. Patients were stratified into 4 categories: Patients with $\mathrm{Hb} \geq 11 \mathrm{~g} / \mathrm{dL}$ and EPO dose $\geq 200$ $\mathrm{IU} / \mathrm{kg} /$ week; patients with $\mathrm{Hb} \geq 11 \mathrm{~g} / \mathrm{dL}$ and EPO dose < $200 \mathrm{IU} / \mathrm{kg} /$ week; patients with $\mathrm{Hb}<11 \mathrm{~g} / \mathrm{dL}$ and EPO dose $\geq 200 \mathrm{IU} / \mathrm{kg} /$ week; and patients with $\mathrm{Hb}<11 \mathrm{~g} / \mathrm{dL}$ and EPO dose $<200 \mathrm{IU} / \mathrm{kg} /$ week. Survival rates were analysed according to these categories. Survival rate was in favour of patients with EPO doses lower than $200 \mathrm{IU} / \mathrm{kg} /$ week and $\mathrm{Hb}$ greater than $11 \mathrm{~g} / \mathrm{dL}$, but this observation 


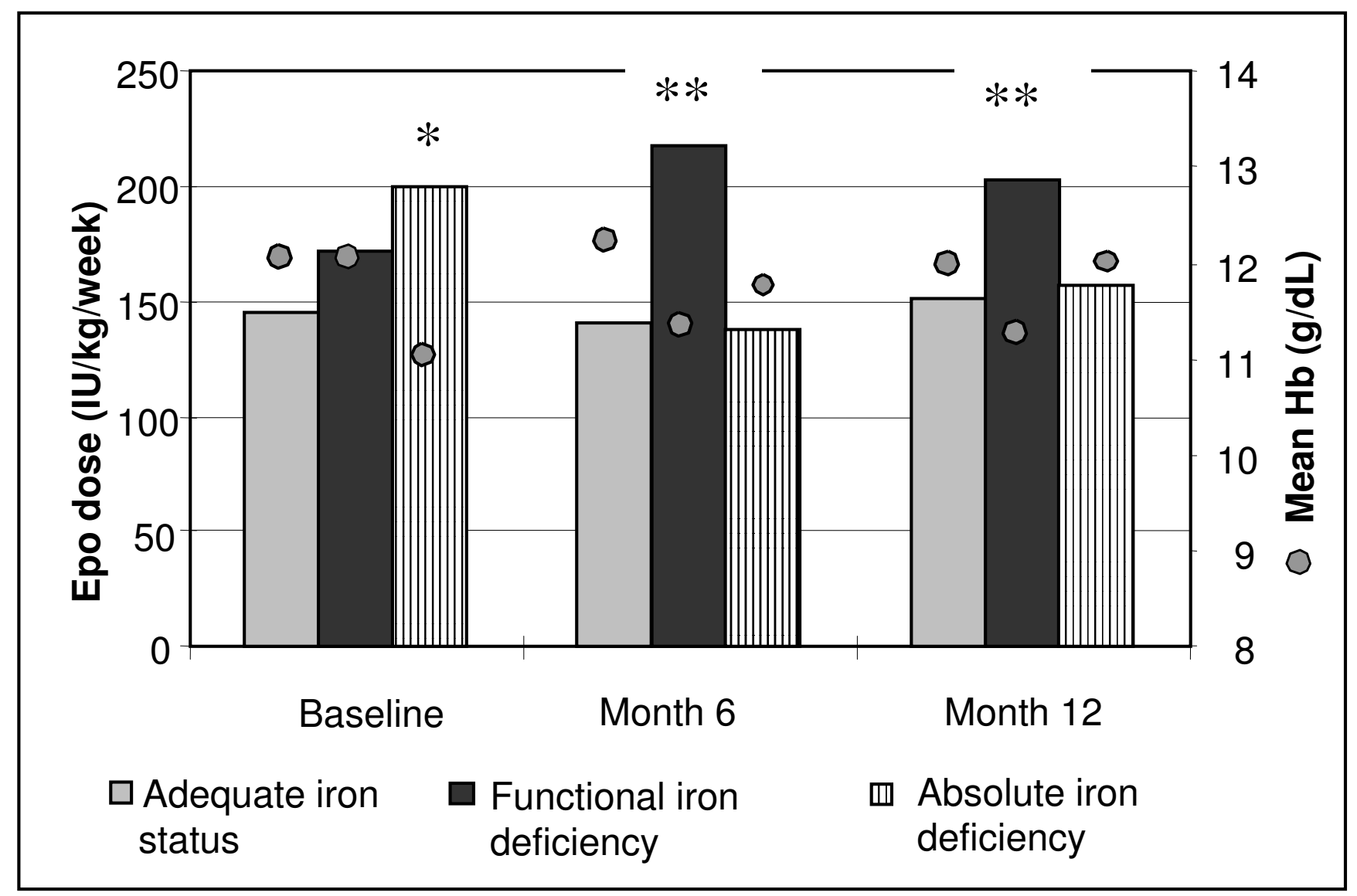

\section{Figure 5}

Influence of iron status on $\mathbf{H b}$ and EPO dose. The iron status was divided into 3 categories, according to ferritin and TSAT (as defined in the text). Values at baseline, month 6 and 12 are shown. $*$ Significant difference observed between patients with "adequate iron status" and "absolute iron deficiency" at baseline. ** Significant difference observed between patients with "functional iron deficiency" and "adequate iron stores" at month 6 ( $p=0.0004$ for $\mathrm{Hb}$ and $p=0.008$ for the EPO dose) and month 12 ( $p=0.03$ for $\mathrm{Hb}$, difference not significant for EPO dose).

failed to reach statistical significance (log rank test: $\mathrm{p}=$ 0.2 ). The same analysis was performed at a cut-off EPO dose of $300 \mathrm{IU} / \mathrm{kg} /$ week, showing a nearly significant lower survival probability in patients with lower Hb levels $(<11 \mathrm{~g} / \mathrm{dL})$ and EPO dose $>300 \mathrm{IU} / \mathrm{kg} /$ week (log-rank test: $\mathrm{p}=0.064)$.

\section{Centre-specific target for $\mathbf{H b}$ and iron status}

In order to understand how this optimal anaemia control was achieved, nephrologists involved in the survey were asked about their personal anaemia management practice, by means of a questionnaire. For $\mathrm{Hb}$, all centres aimed a target above $11 \mathrm{~g} / \mathrm{dL}$, with a range from 11 to 13.5 $\mathrm{g} / \mathrm{dL}$. In 15 of 27 centres (55.5\%), target $\mathrm{Hb}$ was $>12 \mathrm{~g} / \mathrm{dL}$. Regarding serum ferritin, 26 centres aimed values $>200$ $\mu \mathrm{g} / \mathrm{L}$ and 1 centre $>150 \mu \mathrm{g} / \mathrm{L}$. However, $30 \%$ of the centres did not define upper limits as proposed by the EBGP. Fourteen centres (51.8\%) aimed a target range from 200 to $500 \mu \mathrm{g} / \mathrm{L}$ as recommended by the EBPG. For TSAT, 18 centres indicated a target range from 20 to $40 \%$.

\section{Discussion}

With respect to ESAM 1998 [11], ESAM 2003 [7] and DOPPS II [8], this survey demonstrates an optimal anaemia control, obtained in $85 \%$ of patients in a cohort of dialysed patients in Switzerland followed prospectively for 12 months. Mean Hb of $11.9 \mathrm{~g} / \mathrm{dL}$ was remarkably stable throughout the whole observation period.

ESAM 1998 [11] found an overall mean $\mathrm{Hb}$ value of 11.4 $\mathrm{g} / \mathrm{dL}$ with only $49 \%$ of the patients reaching the target level. In ESAM 2003 [7], mean Hb levels were higher than in 1998 (mean Hb of $11.5 \mathrm{~g} / \mathrm{dL}$ with $66.1 \%$ of patients having $\mathrm{Hb}>11 \mathrm{~g} / \mathrm{dL}$ ) in all but two countries. Recent data from the DOPPS II study [8] shows a mean Hb concentration ranging from $10.1 \mathrm{~g} / \mathrm{dL}$ in Japan to $12.0 \mathrm{~g} / \mathrm{dL}$ in Swe- 
den, but with important percentages of patients not meeting the recommended target, even for countries with the highest mean $\mathrm{Hb}$ (Sweden: mean Hb $12.0 \mathrm{~g} / \mathrm{dL}, 23 \%$ of the patients with $\mathrm{Hb}<11 . \mathrm{g} / \mathrm{dL}$; United States: mean $\mathrm{Hb}$ $11.7 \mathrm{~g} / \mathrm{dL}, 27 \%$ of patients with $\mathrm{Hb}<11 \mathrm{~g} / \mathrm{dL} ;$ Spain: mean $\mathrm{Hb} 11.7 \mathrm{~g} / \mathrm{dL}, 31 \%$ of patients with $\mathrm{Hb}<11 \mathrm{~g} / \mathrm{dL}$ ).

In both ESAM studies Switzerland showed a better $\mathrm{Hb}$ control compared to other countries. Looking at previous assessments in Switzerland, the current survey suggests an additional improvement from earlier studies regarding both $\mathrm{Hb}$ (mean $\mathrm{Hb}$ of $11.7 \mathrm{~g} / \mathrm{dL}$ in ESAM 1998 and 11.9 $\mathrm{g} / \mathrm{dL}$ in the current study) and the percentage of patients with $\mathrm{Hb}>11 \mathrm{~g} / \mathrm{dL}(65.1 \%, 78.9 \%$ and $85 \%$ in ESAM 1998, ESAM 2003 and the current study, respectively). It must be stated however that the differences in the nature and design in these studies require cautious interpretation regarding such an improvement. Nonetheless, the current results indicate that Swiss nephrologists have fully integrated EBGP recommendations published in 1999 [11]. The revised version of these guidelines (2004) [9] which proposes to tailor $\mathrm{Hb}$ from 11 to $14 \mathrm{~g} / \mathrm{dL}$ according to comorbidities, age and other factors, was released during the course of the present survey. It is unlikely to have influenced $\mathrm{Hb}$ management in this study. Another Swiss trial, prompted in 2005, is currently examining the impact of the revised EBPG on physician's practice.

Several factors appear to have contributed to these good results: first, our study shows a moderately high mean EPO beta dose, slightly above the upper limit of EBPG recommendations (50-150 IU/ $/ \mathrm{kg} /$ week), with a trend to increase over the 12-months observation period. It is difficult to compare EPO doses between studies focussing on anaemia management, because in ESAM 2003 [7] and DOPPS II [8], EPO doses were not normalized to body weight. Nevertheless, with reference to the mean body weight of our patients, we calculated that mean EPO beta dose was 10'835 IU/week, which was higher than mean EPO used in ESAM 2003 (8'565 IU/week), but comparable to mean EPO doses from 12 countries in DOPPS II (ranging from 5'297 IU/week in Japan to 17'360 IU/week in the US). ESAM 2003 already showed increased mean EPO doses compared to ESAM 1998 [11] in all participating countries, certainly explaining most of the improvement of anaemia control.

Second, the majority (70\%) of our patients received EPO subcutaneously compared to only $22.5 \%$ of the patients in ESAM 2003. Even though mean Hb was comparable in both ways of administration in our study, mean EPO dose was significantly lower for subcutaneous than intravenous administration. This finding confirms the better efficacy of the subcutaneous administration of EPO beta. DOPPS II [8] also reported an EPO dose reduction of about 14\% with subcutaneous administration, though a difference of only $3 \%$ was reported in the US. ESAM 2003 showed that the differences in EPO doses between subcutaneous and intravenous administration were minimal for $\mathrm{Hb}$ values $>11 \mathrm{~g} / \mathrm{dL}$. However, for the intravenous group, EPO doses were substantially higher for lower $\mathrm{Hb}$ values. It is thus conceivable that the major subcutaneous use of EPO in our study may has contributed to the current results.

Third, an adequate iron status is a crucial factor for achieving a satisfactory response to EPO therapy. Almost 73\% of our patients had an adequate iron status. Only a small proportion of the patients $(<10 \%)$ had absolute iron deficiency and only $17.8 \%$ of patients had functional iron deficiency. Less than $10 \%$ had excessive iron stores. In the DOPPS study [8], a larger proportion of patients (35$40 \%$ ) had TSAT $<20 \%$, even though most of them were administered intravenous iron. In ESAM 2003, only $48 \%$ of the patients had adequate iron status and $31 \%$ had TSAT values below 20\% [7]. In order to understand how nephrologists involved in our study managed iron deficiency, we analysed whether the patients with absolute and functional iron deficiency at baseline were corrected during the follow-up. During the whole observation, mean $\mathrm{Hb}$ level was lower and EPO dose higher in patients with "absolute iron deficiency" compared to the group with "adequate iron status". However, mean $\mathrm{Hb}$ of the group "absolute iron deficiency" increased from baseline to month 6 and 12, in parallel to a decrease of EPO requirements, suggesting that physicians attempted to correct for iron deficit. Thus, the management of iron appeared to be adequate. In contrast, we did not observe any $\mathrm{Hb}$ improvement over time in patients with" functional iron deficiency", despite increased use of EPO: this group had overall the lowest $\mathrm{Hb}$ (except at baseline, month 3, 4 and 8) together with the highest dose of EPO (except at baseline). As already shown in ESAM 1998 [11] and 2003 [7], functional iron deficiency has a stronger negative impact on $\mathrm{Hb}$ response rates than absolute iron deficiency. This observation justifies special attention on functional iron deficiency in the future, especially with respect to the role of adjuvant therapy such as vitamin $\mathrm{C}$ and carnitin. Finally, the questionnaire analysis shows that Swiss nephrologists generally refer to EBPG, even if the $\mathrm{Hb}$ target has been higher than recommended for about half of the physicians involved. This strategy may have driven some difficult patients towards a better control.

In order to identify factors potentially affecting anaemia management, we assessed the effect of age, gender, etiologies of end stage renal disease (ESRD) and co-morbidities on $\mathrm{Hb}$ level and EPO dose. Gender had a significant impact on $\mathrm{Hb}$, but not on EPO dose. However, we observed a tendency for females to benefit from higher 
EPO doses, suggesting a fair attempt by nephrologists to equalize $\mathrm{Hb}$ between males and females. There was no obvious effect of age. However, younger age ( $<50$ years) in women tended to influence Hb towards lower levels and, as a possible physician's response, towards higher EPO doses. In addition, older men ( $>60$ years) tended to have lower $\mathrm{Hb}$ than younger men. In ESAM 2003 [7], women also had slightly lower mean $\mathrm{Hb}$ concentration than men, without differences in EPO dose after adjustment for $\mathrm{Hb}$ levels. Age had little effect on $\mathrm{Hb}$ and EPO dose, except for patients aged 70-79 years. In the latter group, $\mathrm{Hb}$ response rate and mean EPO dose were actually below average. In comparison, DOPPS II [8] showed significantly greater $\mathrm{Hb}$ for men, specially for the age group $>75$ years.

Etiologies of ESRD and co-morbidities were demonstrated to determine anaemia control in this study. Diabetes (as a primary renal diagnosis and concomitant disease) was found to influence $\mathrm{Hb}$ to higher values and EPO delivery to a lower dose. Glomerulonephritis influenced EPO to a higher dose, but not $\mathrm{Hb}$. Theses findings were unexpected. ESAM 2003 showed that patients with diabetes were less likely to achieve $\mathrm{Hb} \geq 11 \mathrm{~g} / \mathrm{dL}$ than those with other primary renal diagnosis and concomitant diseases. The reason why diabetic patients have a higher $\mathrm{Hb}$ in our study is not fully explained. However, in our study, patients with diabetes had a significantly higher body weight than non diabetic patients $(78.0 \pm 15.3$ vs $68.0 \pm 9.4 \mathrm{~kg}$; p < 0.0001). A higher fat mass may stimulate erythropoiesis through increased endogenous erythropoietin synthesis and/or sensitivity via the adipocyte hormone leptin $[15,16]$. We indeed observed a significant positive correlation between body weight and $\mathrm{Hb}(\mathrm{p}: 0.0255, \mathrm{r}=0.115)$. It is thus speculated that the higher fat mass in our diabetic patients might be responsible for their increased $\mathrm{Hb}$.

Patients with $\mathrm{Hb}>11 \mathrm{~g} / \mathrm{dL}$ had a significantly better survival compared to patients with $\mathrm{Hb}<11 \mathrm{~g} / \mathrm{dL}$. A trend towards improved survival was also observed with an $\mathrm{Hb}$ cut-off of $12 \mathrm{~g} / \mathrm{dL}$. We also assessed the influence of EPO dose on mortality and found a trend for a lower mortality in patients with $\mathrm{Hb}>11 \mathrm{~g} / \mathrm{dL}$ and EPO dose $<200 \mathrm{IU} / \mathrm{kg} /$ week, compared to the same Hb level but EPO dose $\geq 200$ $\mathrm{IU} / \mathrm{kg} /$ week. These results are consistent with those in DOPPS II, showing a mortality risk to be $5 \%$ lower for every increase of $1 \mathrm{~g} / \mathrm{dL}$ in $\mathrm{Hb}$ concentration. Our data are also in line with the large analysis of Ofsthun et al [17], which showed a mortality benefit for patients beyond the current recommended $\mathrm{Hb}$ target. However, we are aware that observational data, such as those presented in this study, is not sufficient to determine the optimal $\mathrm{Hb}$ target. Indeed, prospective randomized controlled trials showed that complete normalization of $\mathrm{Hb}$ from 126 to $135 \mathrm{~g} / \mathrm{dL}$ has adverse effects on mortality and morbidity parameters such as blood pressure control in chronic kidney disease stages 3 and $4[18,19]$, and on arterio-venous access thrombosis and mortality in dialysis patients [20]. In contrast, quality of life is improved when $\mathrm{Hb}$ is normalised [18]. Thus, a long-standing controversy still exists, especially with regard to the upper limit of $\mathrm{Hb}$ concentration to suggest [21]. The Hb target aimed by Swiss nephrologists in the current study ranged from 11 to $13,5 \mathrm{~g} / \mathrm{dL}$, probably reflecting this controversy.

This survey has several limitations: First, although representing $14 \%$ of the Swiss dialysis population, it includes a relatively small number of patients, which limits its statistical power. Second, we did not look at several parameters known to influence $\mathrm{Hb}$ level and EPO dose, such as residual renal function, adequacy parameters, inflammation/ infection, nutritional parameters, treatment with ACE inhibitors, angiotensin II receptor antagonists and level of iPTH. Third, this is an observational study and even though we paid special attention in order to avoid selection bias, this can't be formally excluded, as there was no random selection into the study. Although exclusion criteria were respected, some unstable patients may have been excluded. This might theoretically have affected our data in a positive fashion. In contrast, some other factors may have had a negative impact on the results: No minimal time on dialysis was requested. It is known that new incident dialysis patients have a lower $\mathrm{Hb}$. We have included twenty EPO-naive patients, who, in general, had a lower $\mathrm{Hb}$ than EPO pre-treated patients. Whether the inclusion of these patients had an influence on mean $\mathrm{Hb}$ was not tested. Nevertheless, in spite of the above limitations, patients included in this study have similar characteristics/co-morbidities compared to ESAM 2003 [7]. With respect to the exclusion criteria, the only selection made was the exclusive use of epoetin beta, as stated in the inclusion criteria. Therefore, the hypothesis that a selection bias may have significantly affected our results in a positive fashion appears unlikely.

\section{Conclusion}

In comparison to ESAM 2003 and DOPPS II, this survey shows an optimal and sustained quality control of anaemia in a cohort of dialysis patients in Switzerland, followed prospectively for 12 months. Such a control was reached through doses of EPO beta in the upper range of EBPG recommendations, preferential use of subcutaneous administration of EPO and careful management of iron therapy.

\section{Competing interests}

Data collection in the dialysis centres was supported by Roche Pharma Switzerland. 


\section{Authors' contributions}

CMM and DT have contributed equally to this article, they analysed and interpreted the data and wrote the article. NL and MB conceived, designed and conducted this survey and corrected the manuscript. LG, DK, PYM were involved in collecting and interpreting data. DG helped to draft the manuscript.

\section{Acknowledgements \\ Participating centres}

Centre Hospitalier Universitaire Vaudois, Lausanne (M.Burnier, D.Teta, C.Mathieu) Hôpitaux Universitaires de Genève, Genève (P-Y.Martin), Kantonsspital, Liestal (D.Kiss), Ospedale Regionale, Locarno (L.Gabutti), Kantonsspital, Aarau (A.Bock), D.Hodel, S.Franz Hirslanden Klinik, Aarau (S.Banyai), Kantonsspital Baden (H.R.Räz), Salem Spital Bern,

(C.Descoeudres, H.Iselin), Lindenhofspital Bern (H.Saxenhofer), Inselspital Bern, (B. Vogt) Hôpital de la Chaux-de-Fonds (M.Giovannini), Hôpital Cantonal de Fribourg (E.Descombes), Regionalspital Interlaken (O.Maurer), Clinique Cécil Lausanne (B.von Albertini), Ambulatorio di nefrologia et dialisi, Lugano (C.Ferrier-Guerra), Kantonsspital Luzern, (A.Fischer), Hôpital régional Martigny (P.Sutter), Hôpital de la Tour Meyrin (P.Guibentif, M.Lévy, S.Thomas), Hôpital du Chablais Monthey (G.Vogel), Dialysestation Münchenstein, (E.Cynke), Centre d'hémodialyse de Nyon (F.Barbey, M.T.Hudry), Centre de dialyse d'Onex, (H.Freudiger), Hôpital Cantonal de Porrentruy (M.Brünisholz), Hôpital Cantonal de Sion, (E.Blanc), Regionalspital Visp (M.Schmied), Hôpital Riviera Vevey (T.Gauthier), Universitätsspital Zürich (R.Wüthrich, P.Ambühl, C. Cao, M.Miozzari). Consultancy: M.Tanner, Swiss Tropical Institute, University of Basel, H.C.Bucher, Clinical Epidemiology, University of Basel. Data management: M.Pfitzenmaier, Dr Köhler $\mathrm{GmbH}$, Freiburg i.Br. Source of funding: This study was supported by Roche Pharma Switzerland Ltd, Reinach.

\section{References}

I. Locatelli F, Pisoni RL, Combe C, et al.: Anemia in haemodialysis patients in five European countries: Association with morbidity and mortality in the Dialysis Outcomes and Practice Patterns Study (DOPPS). Nephrol Dial Transplant 2004, 19:121-132.

2. Ma JZ, Ebben J, $\mathrm{Xia} \mathrm{H}$, Collins $\mathrm{A}$ ): Hematocrit level and associated mortality in haemodialysis patients. J Am Soc Nephrol 1999, 10:610-619.

3. Xia H, Ebben J, Ma JZ, Collins Al: Hematocrit levels and hospitalisation risks in hemodialysis patients. J Am Soc Nephrol 1999, 10:1309-1316.

4. Foley RN, Parfrey PS, Harnett JD, Kent GM, Murray DC, Barre PE: The impact of anemia on cardiomyopathy, morbidity, and mortality in end stage renal disease. Am J Kidney Dis 1996 , 28(I):53-6I.

5. O'Riordan E, Foley RN: Effects of anemia on cardiovascular status. Nephrol Dial Transplant 2000, I 5(suppl 3):S19-S22.

6. Moreno F, Sanz-Guajardo D, Lopez-Gomez JM, Jofre R, Valderrabano $F$ : Increasing the hematocrit has beneficial effect on quality of life and is safe in selected haemodialysis patients. Spanish Cooperative Renal Patients Quality of Life Study Group of the Spanish Society of Nephrology. J Am Soc Nephrol 200I, I I:335-342.

7. Jacobs C, Frei D, Perkins AC, Results of the European Survey on Anaemia Management 2003 (ESAM 2003): Current status of anaemia management in dialysis patients, factors affecting epoetin dosage and changes in anaemia management over the last 5 years. Nephrol Dial Transplant 2005, 20(Suppl 3):iii3-iii24.

8. Pisoni RL, Bragg-Gresham JL, Young EW, Akizawa T, Asano Y, et al.: Anemia Management and Outcomes From 12 Countries in the Dialysis Outcomes and Practice Patterns Study (DOPPS). Am J Kidney Dis 2004, 44:94-III.
9. Locatelli F, Aljama P, Barany P, et al: European Best Practice Guidelines Working Group. Revised European Best Practice Guidelines for the management of anaemia in patients with chronic renal failure. Nephrol Dial Transplant 2004, 19(Suppl 7): $1-45$.

10. NKF-K/DOQI Clinical practice guidelines for anemia of chronic kidney disease. Am J Kidney Dis 200I, 37(I Suppl I):S182-S238

II. Valderrabano F, Hörl W, Jacobs C, Macdougall IC: European Survey on Anaemia Management (ESAM). Nephrol Dial Transplant 2000, I5(suppl 4): I-76.

12. Lacson $E \mathrm{Jr}$, Ofsthun N, Lazarus JM: Effect of variability in anemia management on haemoglobin outcomes in ESRD. Am J Kidney Dis 2003, 4I: I II-I 24.

13. Berns JS, Elzein H, Lynn RI, Fishbane S, Meisels IS, Deoreo PB: Hemoglobin variability in epoetin-treated haemodialysis patients. Kidney Int 2003, 64:15|4-1521.

14. Fishbane S, Berns JS: Hemoglobin cycling in hemodialysis patients treated with recombinant human erythropoietin. Kidney Int 2005, 68: I337-I343.

15. Stenvinkel P, Heimburger O, Lonnqvist F, Barany P: Does the ob gene product leptin stimulate erythropoiesis in patients with chronic renal failure? Kidney Int |998, 53:|430-|43|.

16. Axelsson J, Qureshi AR, Heimburger O, Lindhom B, Stenvinkel P, Barany P: Body fat mass and serum leptin levels influence epoetin sensitivity in patients with ESRD. Am J Kid Dis 2005, 46:628-634

17. Ofsthun N, Labrecque J, Lacson E, Keen M, Lazarus JM: The effects of higher hemoglobin levels on mortality and hospitalization in hemodialysis patients. Kidney Int 2003, 63:1908-1914.

18. Drueke TB, Locatelli F, Clyne N, et al.: Normalization of hemoglobin level in patients with chronic kidney disease and anemia. N Engl J Med 2006, 355:207I-2084.

19. Singh AK, Szczech L, Tang LK, et al.: Correction of anemia with epoetin alfa in chronic kidney disease. N Engl J Med 2006, 355:2085-2098.

20. Besarab A, Bolton WK, Browne JK, et al.: The effects of normal as compared with low hematocrit values in patients with cardiac disease who are receiving hemodialysis and epoetin. $N$ Eng J Med 1998, 339:584-590.

21. Phrommintikul A, Haas SJ, Elsik M, Krum H: Mortality and target hemoglobin concentrations in anaemic patients with chronic kidney disease treated with erythropoietin: a meta-analysis. Lancet 2007, 369:38I-389.

\section{Pre-publication history}

The pre-publication history for this paper can be accessed here:

http://www.biomedcentral.com/1471-2369/9/16/prepub

Publish with Bio Med Central and every scientist can read your work free of charge

"BioMed Central will be the most significant development for disseminating the results of biomedical research in our lifetime. "

Sir Paul Nurse, Cancer Research UK

Your research papers will be:

- available free of charge to the entire biomedical community

- peer reviewed and published immediately upon acceptance

- cited in PubMed and archived on PubMed Central

- yours - you keep the copyright
BioMedcentral 